\title{
Unequal Pricing in the Information Economy: Implications for Consumer Welfare
}

\begin{abstract}
This article presents an economic analysis of information good pricing and consumer welfare, and discusses the implications of price discrimination in the information economy. It argues that network externalities, coupled with information asymmetry, enable a dominant marketer to price unequally, extracting late adopters' surplus to compensate for the loss from early adopters. In the short term, the minority early adopters benefit by paying less, but in the long term, the majority late adopters suffer by paying more. Considering that late adopters are likely to be at a disadvantage in resources, this discriminatory pricing amounts to the poor subsidizing the rich. Based on this analysis, implications for consumer welfare are discussed.
\end{abstract}

KEY WORDS: Information good, consumer welfare, unequal pricing, discriminatory pricing, network externalities, information asymmetry

\section{Introduction}

The Internet makes cost information easily available, and presumably consumers can see costs and determine whether they are in line with the prices being charged elsewhere. Varying pricing strategies are proposed to counteract this competitive force online such as so-called "smart pricing" (charging different consumers different prices for the same goods) (Sinha, 2000). Accordingly, the importance of price as a strategic marketing variable and concern for the public's welfare have increased significantly. Technological advances have made it possible to collect much more data than previously about marketers, the markets, consumers, and the information on which marketers base their pricing strategies (Grewal

Mine-Hui Huang is a professor in the Department of Information Management at the National Taiwan University. and Compeau, 1999). Thus the opportunity for unequal pricing and consumer harm created by this aspect of Internet use must be considered.

In this article, we examine the issue of unequal pricing on the Internet. We develop exploratory propositions to address the supply and demand characteristics of information goods, which demonstrate network externalities, and assess the various consequences of discriminatory pricing strategies for consumer welfare. Our intent is to offer consumer welfare and managerial insights into this unequal pricing issue facing marketing organizations in the new economy.

\section{The information goods market}

The expanding information technology that underlies the evolving economy is a driving force, fundamentally changing the economy (Stiroh, 1999). Information goods constitute the core products and services that are exchanged in the network-based electronic markets. These markets can be characterized as the means by which marketers and consumers share information, exchange transactions, and coordinate processes over telecommunication networks (Truman, 2000). Two characteristics define network markets: (1) network externalities, both in the production and consumption sides, lead to winner-takeall markets, and (2) the flow of information between marketers and consumers is asymmetrical.

First, in electronic markets, networks constitute the context in which information goods are exchanged, and the utility of the goods exchanged is a function of the size of the network. Marketers in network markets tend to form monopolies as a result of the high fixed initial cost to produce 
information goods (Shapiro and Varian, 1999, p. 3) and the production-side economies of scale (Bakos and Brynjolfsson, 2000). Dewan et al. (2000) affirmed that the fixed cost of getting information goods online is so high that in equilibrium only a single content provider exists on the network. Streeter et al. (1996) argued that marketers in the electronic network marketspace competing on the basis of price could use the network to broaden their consumer base and lower costs. Bakos and Brynjolfsson (2000) showed that bundling a larger number of information goods could create economies of aggregation, even in the absence of network externalities or economies of scale or scope. When competing for upstream content, larger bundlers are able to outbid smaller ones. The act of bundling information goods makes an incumbent competing for downstream consumers seem tougher to singleproduct competitors selling similar goods. The resulting equilibrium is less profitable for potential entrants and can discourage entry into the bundler's markets, even when the entrants have a superior cost structure or quality. From the consumer side, the net-centric feature gives the markets a fundamental economic characteristic: the value of connecting to the markets and obtaining information goods depends on the number of other consumers already connected to it (Shapiro and Varian, 1999, p. 174). Information goods sold in network markets demonstrate externalities of consumption that leave consumers with high switching costs and thus benefit the dominant marketers.

Second, network markets allow consumers to become more informed about marketers in the marketspace and their product offerings, and marketers can access information on the needs of consumers. However, the collection and distribution of information such as product performance evaluations is costly (Avery et al., 1999). Information technology capitalization is likely to be asymmetrical between marketers and individual consumers, resulting in information asymmetry (Grover and Ramanlal, 1999). In the language of game theory, information asymmetry implies that each player has private information about his or her strategies, although the information may or may not be complete (Kulkarni, 2000) When differences in the availability of resources between marketers and consumers exist, marketers know consumers' demands better than consumers know marketers' offerings. Caudill and Murphy (2000) pointed out that in the decentralized, open, and interactive new e-mail setting, consumers could engage in commerce and search for information. However, these factors bring a downside for consumers. Because their activities are conducted electronically, consumers leave a trail of information that includes not only purchasing information but also data pertaining to their interests and activities, which allow online marketers the opportunity to develop profiles of individual consumers.

\section{Demand and break-even with network externalities}

\section{Break-even with network externalities}

The production of information goods involves a high level of sunk fixed costs, yet their distribution and reproduction entails almost zero marginal costs (Bakos and Brynjolfsson, 1999, 2000; Dewan et al., 2000; Shapiro and Varian, 1999, p. 22; Varian, 2001). This unique cost structure naturally gives rise to (1) network externalities of production because average costs decrease as the network size increases, and (2) monopoly because competition can force prices close to an undesirable zero and marketers are unlikely to enter a market with such a cost structure.

Hence, we consider a dominant marketer who wants to maximize expected profit over time. Assume that the quantity of information goods sold increases monotonically with the size of the network market. It is desirable for the marketer to establish a large consumer base to earn enough revenue to break even. The break-even curve would start a price equal to the cost of establishing the information system and then decrease, with the marginal costs of information goods reproduction approaching zero. The average costs give a schedule of break-even prices for information goods similar to that seen in Figure 1, rather than the marginal cost curve.

This downward break-even curve suggests that as the size of the network market approaches infinity, only interaction costs incur when the marketer and consumers exchange information goods (Smith, 1999). It has been observed with online stock 


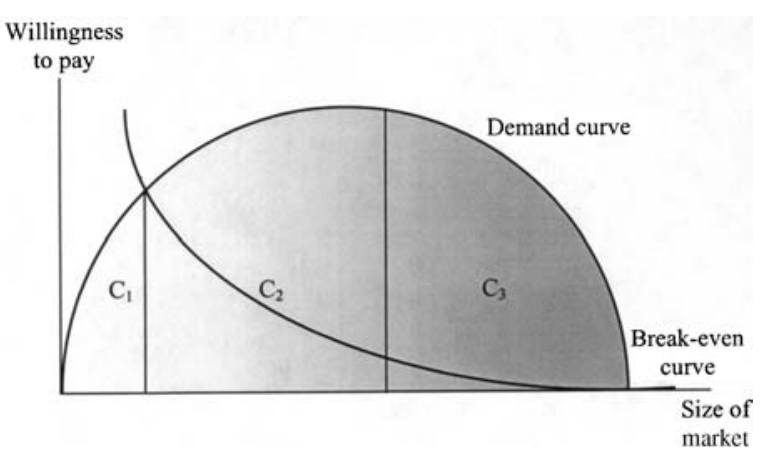

Figure 1. Demand and break-even with network externalities.

trading that the cost for commissions and transactions on electronic exchanges will trend toward zero (Teschler, 2000). In this case, the break-even curve leads the market toward a monopoly because the level of output that minimizes average costs is large relative to the size of the market (Varian, 2003, pp. 432-433). This insight is given in Proposition $P_{1}$.

$P_{1}$ : The break-even price of information goods will be at its averaged cost curve, which decreases with the size of the market and tends to approach zero marginal cost.

\section{Demand with network externalities}

The demand for information goods is assumed to be function of price, market size (i.e. cumulative sales), and consumers' innovativeness. According to Varian (2001, 2003, pp. 631-634), the price of information goods and the number of consumers that are connected to the network create a hump-shaped demand curve for information goods.

Varian's stylized model is sufficient to capture the important features of this type demand curve; it is easily generalized to more complex or realistic settings. There are $N$ consumers of the information good, and each has a reservation price $v=1, \ldots, N$. That is the consumers are ordered according to their reservation value from lowest $(v=1)$ to highest $(v=N)$. For an individual consumer, the total value or maximum willingness to pay for the information good depends on the number of persons connected to network. When $n \leq N$ consumers are connected, an individual consumer has total value of $v n$. At price $p$ for the information good, any consumer with $v n>p$ will want to connect. The marginal consumer is indifferent to obtaining the information good. Denoting her reservation value a $\hat{v}$, the price of the information good is given by

$p=\hat{v} n$.

Every consumer with a higher value of $v$ than $v$ must want to connect. In this model, then, the number of consumers that want to obtain the information good can be expressed as

$n=N-\hat{v}$.

Thus $\hat{v}=N-n$, and substituting this into Equation (1) yields the demand relation between price and the size of the network

$p=(N-n) n=N n-n^{2}$.

As shown above in Figure 1, this quadratic or hump-shaped demand curve intersects the horizontal axis at $n=0$ and $n=N$, and reaches its peak or maximum at $d p / d n=N-2 n=0$ or $n=N / 2$.

Both price and market size explain the shape of the demand curve for information goods, but for a given target market, who prefers to connect and buy first and who prefers to wait? Some consumers are more innovative and will try out information goods in the electronic market earlier than others. As defined by Rogers (1983), a consumer's innovativeness is "the degree to which an individual is earlier in adopting new ideas than the other members of his social system." Rogers distinguished five adopter categories following a bell-form curve as a function of time: innovators, early adopters, early majority, late majority, and laggards. Few studies have actually used more than three categories because of the difficulty in distinguishing the consumers who make up each category (Martinez and Polo, 1996). American Demographics (1999) used a three-category classification for personal computer banking. Early majority (10\%) includes innovators and early adopters who are willing to try new products early. Middle majority (46\%) includes the enthusiastic subgroup that exhibits early majority characteristics and the traditionalist subgroup that shows late majority characteristics. Late majority or laggards (44\%) adopt the innovation only when it takes on a measure of tradition itself. 
Putting Equation 3 and consumers' innovativeness together, we can obtain the aggregate demand curve for the information good depicted in Figure 1, which first increases and then decreases. If the number of early adopters that connect is low, then the marginal consumer's willingness to pay is low, because there aren't many other consumers out there with whom the consumer can exchange information. If a large number of late majority consumers are connected, then the marginal consumer's willingness to pay is again low, because every consumer that valued the information more highly has already connected. Thus a consumer's demand for the information good is given by his marginal willingness to pay. Proposition $\mathrm{P}_{2}$ states this prediction.

$P_{2}$ : The demand curve of information goods is given by the marginal willingness to pay, which first increases and then decreases with the number of consumers connected to the market.

\section{Pricing and consumer welfare}

\section{Consumers' surplus}

Have consumers experienced a gain or loss from market networking and its distribution of information goods? To answer this question, consumers' surplus has been suggested as the approximate measure of consumer welfare (e.g. Brynjolfsson, 1996; Joesch and Zick, 1990; Stennek, 1999). Following Grover and Ramanlal (1999), consumers' surplus is defined as the difference between the maximum amount consumers are willing to pay for each successive unit of the information good and the market price set by the dominant marketer. By adding up each individual consumer's surplus or by integrating the area under the demand curve between the current price $\left(p_{0}\right)$ and the new price $\left(p_{1}\right)$, one can obtain the total value of consumers' surplus from a price change (Brynjolfsson, 1996).

Surplus $=\int_{P_{0}}^{P_{1}}$ Demand $($ Price, Income $) d($ Price $)$.
The division of consumer welfare between the marketer and consumers (Grover and Ramanlal, 1999) and between consumer segments has implications for the information economy. One must make a value judgment about the relative welfare of the marketer and consumer to determine a better market arrangement (Varian, 2003, p. 426).

\section{Consumer heterogeneity}

The preference for information goods will not be identically distributed. Consumers differ in their preferences and thus in their timing in purchasing information goods. Consumer segments for information goods in the electronic market can be profiled on the basis of their innovativeness as well as the utility that consumers derive from network externalities. Some consumers will try out innovations earlier than others.

Speaking in terms of the three broad adopter categories discussed earlier, early adopters $\left(\mathrm{C}_{1}\right.$ in Figure 1) expect attractive benefits from information goods due to their needs, and this group experiences such needs ahead of the majority of the target market (Morrison et al., 2000). They tend to have higher social status and a more favorable financial position (Bushy and Kamphuis, 1993; Martinez and Polo, 1996; Rogers, 1983). Jain et al. (1999) identified two segments for cellular phones and phone call markets, with the heavy-user segment predominately consisting of business/professional users and the light-user segment blue collar and personal end users. Early adopters will connect to the market and buy the information goods first. Although they expect positive utility from information goods in the future, they do not place a high value on those goods because there are not sufficient consumers in the market to realize the network value of the information goods. However, their positive utility expectation coupled with their innovativeness makes them the segment that will connect first but with a low willingness to pay. As early adopters are by definition ahead of the bulk of the target market with respect to their needs, an attractively sized early adopter market may not exist from the dominant marketer's point of view (Morrison et al., 2000).

The middle majority of critical mass $\left(\mathrm{C}_{2}\right)$ purchases the information goods immediately before 
and after the peak of the demand curve. The peak represents a "critical mass" of consumers that have purchased the information goods and provide positive feedback to kick in the success of the goods (Varian, 2001). The $\mathrm{C}_{2}$ segment derives higher utility from the information goods because the $\mathrm{C}_{1}$ segment has created a low level of network externalities of consumption. According to whether the middle majority will purchase at an increasing or decreasing part of the demand curve, this segment can be further divided into two or three subgroups (American Demographics, 1999; Kuznesof and Ritson, 1996). Kuznesof and Ritson (1996) noticed two subgroups in the middle majority. The enthusiastic subgroup exhibits typical early adopter characteristics and is more predisposed to appreciate the benefits of technology, whereas the traditionalist subgroup shows late majority characteristics and is more sensitive to price because of their lower disposable incomes. The market may not be able to identify the subgroups of the middle majority because although they are quite different from the early adopters and late majority, they are not strongly differentiated from each other (American Demographics, 1999).

The late majority segment $\left(\mathrm{C}_{3}\right)$ includes consumers who will purchase the information good at the decreasing part of the demand curve. Although they are low in innovativeness, after having witnessed the positive utility outcomes for $\mathrm{C}_{1}$ and $\mathrm{C}_{2}$, they are willing to buy. Their willingness to pay for the information goods is relatively high because $\mathrm{C}_{1}$ and $\mathrm{C}_{2}$ together create a high level of network externalities that add value to the information goods. The willingness to pay decreases as consumer segments $\mathrm{C}_{1}$ and $\mathrm{C}_{2}$ who value the information good more than $\mathrm{C}_{3}$ users do, have connected. Assumption $\mathrm{A}_{1}$ incorporates consumer heterogeneity with respect to innovativeness into the network market for information goods depicted in Figure 1.

$A_{1}$ : Early adopters $\mathrm{C}_{1}$ buy at the increasing part of the demand curve, the middle majority $\mathrm{C}_{2}$ buys immediately before and after the peak of the demand curve, and the late majority $\mathrm{C}_{3}$ buys at the decreasing part of the demand curve.
Price at demand curve

Information goods are often priced according to the value consumers place on them (Kotler, 2000, p. 468; Shapiro and Varian, 1999, p. 43) to avoid the undesirable result of pricing at zero marginal costs. This pricing strategy requires that marketers have full information on the demand, an assumption often deemed unpractical (e.g. Masuda and Whang, 1999). Yet, in a network market this assumption is plausible because the dominant marketer with superior information technology capitalization can more readily obtain information about consumer demand (Grover and Ramanlal, 1999). The information asymmetry between the dominant marketer and consumers, and consumer heterogeneity in preference for information goods influence the probability of the dominant marketer acting opportunistically. This has significant implications for price discrimination (Kulkarni, 2000) and resultant consumer welfare. Guiltinan and Gundlach (1996) pointed out that the presence of informational asymmetries permits marketers to induce consumers to act according to their intentions. Shapiro and Varian (1999, pp. 33-34) argued that asymmetric information is critical for differential pricing on the Internet: the marketer needs to learn about consumers to reap substantial rewards. If information flows between the marketer and consumers are symmetric, both sides would have equal bargaining and information power, then the competitive outcome would apply.

With asymmetric information, the dominant marketer can take advantage of knowing consumer preference among various consumer segments or even that of individual consumers to employ price discrimination to sell each unit of information good at its demand price (Howell, 1991; Shapiro and Varian, 1999, pp. 40-43) and extract all consumers' surplus. In this case, Assumption $A_{2}$ will hold.

$A_{2}$ : With information asymmetry, marketers can price information goods at the demand curve to extract the consumers' surplus.

\section{Profit-maximizing discriminatory pricing}

For a monopolist the market price is a markup over marginal cost, with the amount of markup 
depending on the elasticity of demand (Varian, 2003, p. 423). Following Varian (1992, pp. 248-250) and considering consumer innovativeness, it is feasible for

$$
\begin{aligned}
p_{c 3}\left(q_{c 3}\right)> & p_{c 1}\left(q_{c 1}\right)>p_{c 2}\left(q_{c 2}\right) \\
& \text { if and only if }\left|\varepsilon_{c 2}\right|>\left|\varepsilon_{c 1}\right|>\left|\varepsilon_{c 3}\right| .
\end{aligned}
$$

For non-network goods, $\left|\varepsilon_{c 3}\right|>\left|\varepsilon_{c 2}\right|>\left|\varepsilon_{c 1}\right|$, that is, early adopters $\mathrm{C}_{1}$ are least price-sensitive, followed by middle majority $\mathrm{C}_{2}$ and late majority $\mathrm{C}_{3}$. It has long been demonstrated that greater levels of innovativeness are associated with lower price sensitivity (Goldsmith and Newell, 1997), probably because early adopters have a higher than average income level (Amesse et al., 1991). For network goods, $\left|\varepsilon_{c 2}\right|>\left|\varepsilon_{c 1}\right|>\left|\varepsilon_{c 3}\right|$, because additional utility can be obtained when more consumers connect and disutility is generated when more consumers are locked in. The late majority $\mathrm{C}_{3}$ is least price-sensitive because when every consumer that values the goods more highly has already connected, the goods have now become basic goods; they can either pay the monopoly price $p_{\mathrm{c} 3}$ and consume $q_{c 3}$, or consume zero units of the goods (Varian, 2003, p. 629).

Consequently, for $\mathrm{C}_{1}$ consumers, the marketer would behave competitively and price at $p_{\mathrm{c} 1}$, the demand curve, which falls below the break-even price, in an effort to create a market that did not previously exist and to stimulate growth early in the life cycle of the goods (Varian, 2003, p. 637). This practice is known as "penetration pricing" such that the marketer offers early adopters a lower price to invade the market (Shapiro and Varian, 1999, p. 288, Varian, 2001). This will result in $q_{c 1}$ market share, and $\mathrm{C}_{1}$ consumers would retain no surplus (see Figure 2a).

For $\mathrm{C}_{2}$ consumers, the marketer would similarly behave competitively and price at $p_{c 2}$, the breakeven price. Although there are potentially subgroups of $\mathrm{C}_{2}$ consumers that vary in willingness to pay, it may not be sensible for the marketer to price-discriminate $\mathrm{C}_{2}$ subgroups for two reasons: First, for the high-fixed-cost and zero-marginalcost information market, the marketer would need to lower the price and make up for it in volume (Shapiro and Varian, 1999, pp. 27-28) in order to establish network externalities to deter competition (Varian, 2003, p. 637). When there is competition to acquire market dominance, consumers would be better off than when there is no such competition (Varian, 2001). Second, because the $\mathrm{C}_{2}$ subgroups are not strongly differentiated, the marketer may not be able to price discriminately on the basis of exogenous, observable characteristics of $\mathrm{C}_{2}$ consumers. Thus, the marketer will charge the lowest break-even price to entice the whole middle majority. ${ }^{1}$ This practice is known as "limit pricing" such that the marketer sets prices as high as possible without encouraging others to invest the sunk costs necessary to enter the market (Shapiro and Varian, 1999, p. 30). Pricing at this stage is designed to achieve volume-oriented objectives, to trade short-term profits for longterm gains (Guiltinan and Gundlach, 1996).

For $\mathrm{C}_{3}$ consumers, the marketer would behave monopolistically and price at the demand $p_{\mathrm{c} 3}$ to
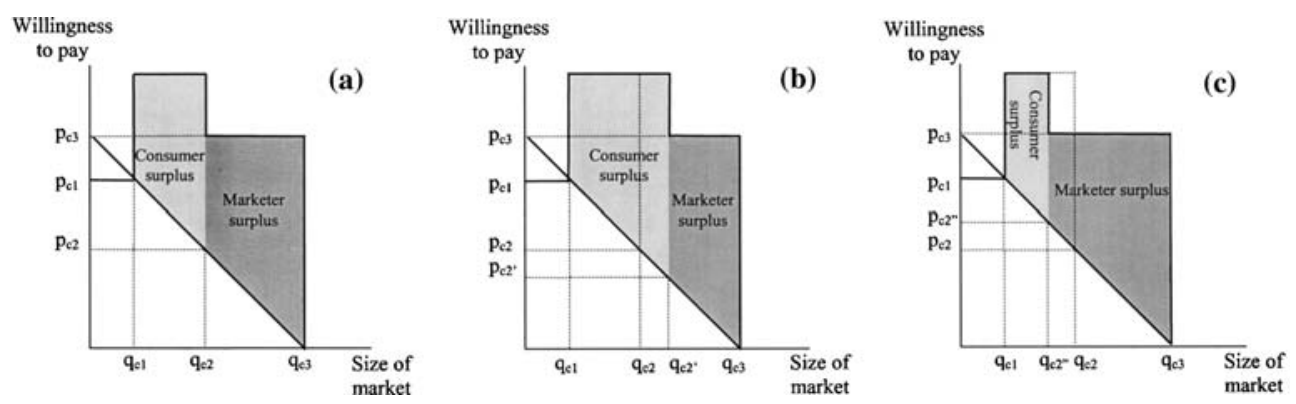

Figure 2(a). Pricing and consumers' surplus, (b) Price and surplus change when $q_{\mathrm{c} 2}$ increases, (c) Price and surplus change when $q_{c 3}$ decreases.

Note. The smooth demand and break-even curves shown in Figure 1 are depicted here as linear to show propositional changes in the three consumer segments. 
realize monopoly profits, because the marketer has established network externalities to entice and lock $\mathrm{C}_{3}$ consumers in. This late majority segment places a lower value on the information goods than the $\mathrm{C}_{2}$ segment (that is why they adopt late), but has to pay a price higher than $\mathrm{C}_{2}$. The $\mathrm{C}_{3}$ consumers are made worse off as a result of the monopoly taking away all their surpluses. As observed in Jain et al. (1999), the prices for phonecall markets demonstrating network externalities were found to remain high with the increased size of the markets. This is a profit-maximizing strategy at the consumer's expense that takes advantage of network externalities. In this market situation, the $\mathrm{C}_{2}$ segment is used to entice the profitable $\mathrm{C}_{3}$ segment. Once a minimum sufficient number of consumers is locked in, all followers will be charged at the high price $p_{c 3}$ without justification for the higher cost. Proposition $\mathrm{P}_{3}$ gives this discriminatory pricing.

$P_{3}$ : Given Assumptions $\mathrm{A}_{1}$ and $\mathrm{A}_{2}$, early adopters $\mathrm{C}_{1}$ will be charged at the demand price, middle majority $\mathrm{C}_{2}$ will be charged at the breakeven price, and late majority $\mathrm{C}_{3}$ Will be charged at the demand price for the information goods.

\section{Alternative discriminatory pricing}

Varying the prices charged to $\mathrm{C}_{2}$, we can see changes in prices and consumers' surplus. Implementing penetration pricing deeper at the breakeven $p_{c_{2}^{\prime}}$, the dominant marketer increases $\mathrm{C}_{2}$ size from $q_{\mathrm{c} 2}$ to $p_{c_{2^{\prime}}}$, with more $\mathrm{C}_{2}$ consumers perceiving gains in utility and buying earlier (see Figure $2 \mathrm{~b}$ ). In this market-share-building strategy, the marketer relinquishes a greater proportion of surplus to $\mathrm{C}_{2}$ consumers as incentives for them to buy, as shown in the enlarged gray area. Hence, the enthusiastic $C_{2}$ consumers exert a positive externality on those traditionalist $\mathrm{C}_{2}$ consumers who buy now rather than later, in contrast to the results shown in Figure 2a. The fact that $\mathrm{C}_{2}$ is served constitutes a necessary condition for welfare to increase under discriminatory pricing (Varian, 1985). $\mathrm{C}_{2}$ consumers are able to retain the increased welfare. This leads to Proposition $\mathrm{P}_{4}$.
$P_{4}$ : Given Proposition $\mathrm{P}_{3}$, consumers retain a greater proportion of surplus than the marketer with an increasing size of middle majority $\mathrm{C}_{2}$.

Figure $2 \mathrm{c}$ depicts skimming pricing, where the dominant marketer raises the price charged to $\mathrm{C}_{2}$ from $p_{c 2}$ to $p_{c 2}$ to realize returns on investments earlier and the resultant decrease in $\mathrm{C}_{2}$ size from $q_{c 2}$ to $q_{c 2}$, Facing a higher price, the traditionalist $\mathrm{C}_{2}$ consumers will behave like $\mathrm{C}_{3}$ consumers and delay their purchases. With a reduced output, consumer welfare is decreased. The decrease in the size of $\mathrm{C}_{2}$ correspondingly increases the size of $\mathrm{C}_{3}$. However, $\mathrm{C}_{3}$ will be charged at the demand curve $p_{c 3}$, given the monopolistic nature of the market and network externalities of consumption. With an enlarged $\mathrm{C}_{3}$ segment being served, welfare increases but is retained by the marketer due to its market power. As shown by the shrunken gray area in Figure 2c, the surplus retained by consumers will decrease. Proposition $\mathrm{P}_{5}$ gives the relationship between skimming pricing and consumers' surplus.

$P_{5}$ : Given Proposition $\mathrm{P}_{4}$, consumers retain a lower proportion of surplus with an increase in the size of late majority $\mathrm{C}_{3}$.

\section{The unequal distribution of surplus}

The discriminatory pricing strategies delineated in Proposition $\mathrm{P}_{3}$ will lead the dominant marketer to have zero producer surplus in the early adopter $C_{1}$ segment and extract all consumer surplus from the late majority $\mathrm{C}_{3}$ segment. The welfare effect is ambiguous for the middle majority $\mathrm{C}_{2}$ segment because subgroups are served under flat pricing (Varian, 1997).

We can compare a uniform pricing strategy to the discriminatory pricing strategy depicted in Proposition $\mathrm{P}_{3}$ to examine changes in the division of welfare between the marketer and consumers and among the consumer segments. When only $\mathrm{C}_{1}$ is served, there is no surplus because the information goods are sold below the break-even curve at $p_{c 1}$. When both $\mathrm{C}_{1}$ and $\mathrm{C}_{2}$ are served and charged discriminately at $p_{c 1}$ and $p_{c 2}$, respectively, the market size increases to $q_{c 2}$. The growth in market size increases surplus, which is retained by $\mathrm{C}_{2}$ consumers. Finally, when $\mathrm{C}_{1}, \mathrm{C}_{2}$ and $\mathrm{C}_{3}$ are all served and charged at $p_{c 1}, p_{c 2}$, and $p_{c 3}$, 
respectively, the market size increases to $q_{c 3}$. The $\mathrm{C}_{2}$ consumers will retain their surplus, whereas the marketer will extract all $\mathrm{C}_{3}$ consumers' surplus. Consequently, when all $\mathrm{C}_{1}, \mathrm{C}_{2}$, and $\mathrm{C}_{3}$ segments are considered, whether the marketer or consumers retain a greater proportion of surplus depends on the relative size of the $\mathrm{C}_{1}$ versus $\mathrm{C}_{3}$ segment. The larger the $\mathrm{C}_{3}$ segment the greater the amount of surplus retained by the marketer. Since the size of $\mathrm{C}_{3}$ is typically larger than $\mathrm{C}_{1}$, the dominant marketer will end up retaining a greater proportion of surplus.

Under such circumstances, there is a concern about the unequal distribution of surplus, because the poor are charged higher prices to compensate for losses by the rich in an effort to realize higher profits in the long run (Grewal and Compeau, 1999). The marketer's gain in surplus is taken from $\mathrm{C}_{3}$ to compensate the loss in surplus from $\mathrm{C}_{1}$ and $\mathrm{C}_{2}$. The $\mathrm{C}_{3}$ segment comprises the majority of the consumer population, who are likely to have a lower social status and be in an unfavorable financial position relative to the $C_{1}$ and $C_{2}$ segments (Rogers, 1983). This discriminatory pricing results in the poor paying more for information goods.

Information asymmetry aggravates this problem. If information flows between the marketer and consumers are symmetric, both sides would have equal information power to bargain, and then the marketer would not be able to price at demand. If information flows between consumers are symmetric, consumers would have equal information power to assess the value of information goods, and then envy between consumers would not occur. Hence, with symmetric information flow, the market allocation can be considered as fair because it is both equitable and Pareto efficient (Varian, 1974). For example, Kulkarni (2000) argued that the information level of a consumer segment is a function of the resources available to that segment, among other things. With insufficient resources to buy early and to assess the cost of information goods, the poor lose their surplus to the marketer.

\section{Discussion}

The key insight of this analysis is that with pricing discrimination, an information goods marketer can create monopolization through network externali- ties and information asymmetry, which will result in the poor subsidizing the rich, the marketer extracting a disproportional surplus, and an aggregate loss in welfare. The propositions predict that the early adopter $\mathrm{C}_{1}$ segment does not value the information goods highly but, motivated by inherent innovativeness, is attracted by the low prices. The interest shown by $\mathrm{C}_{1}$ then signals the value of the information goods to $\mathrm{C}_{2}$ and increases $\mathrm{C}_{2}$ 's valuation of the goods. The joining of $\mathrm{C}_{2}$ creates network externalities and brings additional utility to $\mathrm{C}_{1}$, and both segments benefit. Witnessing the positive utility outcome of $\mathrm{C}_{1}$ and $\mathrm{C}_{2}$, and observing the low prices they paid, $\mathrm{C}_{3}$ will form a false positive expected utility of buying the goods at even lower prices, which unfortunately will not be fully realized. This pricing results in an equal distribution of surplus in that the cost of supplying the information goods decreases with the size of the market and the network benefit brought about by consumers is retained by the marketer rather than left to the consumers. Further, the marketer surplus is extracted from the majority poor, who have less information and resources to connect and buy early for the price advantage, but find themselves locked in the cost of changing to a different marketer is so high that switching is virtually inconceivable (Varian, 2003, p. 629). The pricing strategies delineated here offer the following managerial and consumer welfare implications.

\section{Managerial implications}

A marketer would argue that charging $\mathrm{C}_{3}$ at the demand curve is value pricing since consumers are paying what they value. However, considering the low marginal cost of reproducing information goods, this practice involves overpricing. An alternative argument would be that the discriminatory pricing is a natural outcome of a product life cycle, with introduction and growth stages using low prices to gain share, and maturity and decline stages using high prices to realize returns on investment. However, a typical product life cycle curve is based on the perfect competitive market assumption that as the market grows, more competitors enter the market and price can remain only at the marginal cost of production 
under competition. Hence, the pricing strategy discussed here may not be justified, even with the arguments of value pricing and product, life cycle pricing.

\section{Consumer welfare implications}

First, the current analysis Predicts that marketers will initially price information goods below breakeven, then at break-even, and finally at demand, with network externalities and information asymmetry facilitating the formation of a monopoly. Could consumers possibly benefit from a policy limiting the market share of the dominant marketer? Given the above analysis, it can be seen that in the near term, the policy would be bad for consumers because an output constraint on the dominant marketer would raise the initial price and reduce welfare. However, the policy might reduce the future price as increased competition disciplined the future pricing behavior of the dominant marketer. In such a case, the policy would have a welfare tradeoff for consumers: a cost in the initial period and a benefit in a future period.

Second, value pricing as a common practice for pricing information goods as given in Assumption $\mathrm{A}_{2}$ brings consumer harm that is of concern. Using software as an example, Grewal and Compeau (1999) questioned the pricing practice of identical software being priced differently depending on whether it is sold to an individual for personal use or to one who uses it for a business. One line of thinking about this problem is that marketers should compensate for consumers' loss in surplus by paying for the demand information they collect from consumers. To be able to price at demand, marketers require information from consumers, and the information should constitute part of the price exchanged. In discussing the asymmetric information relationship between marketers and consumers, Caudill and Murphy (2000) argued that information obtained by marketers without providing equivalent value to consumers and the subsequent feeling of a loss of control by these consumers suggests that at some time in the future consumers may demand retribution, through either government action or boycott. Another approach would be to facilitate the symmetry of information flow. A consumer's inability to make a purchase decision with complete information and to buy at a fair price suggests an asymmetrical relationship in which the marketer benefits at a cost to the consumers (Caudill and Murphy, 2000). If information flow were symmetrical, the network markets would become competitive in that information goods would be exchanged to maximize welfare.

\section{Conclusion}

This analysis examined price discrimination with network externalities and information asymmetry, and its impact on consumers. With network externalities, small new market entrants are less likely to be able to compete with the dominant marketer, and with information asymmetry, the dominant marketer is more likely to be able to extract the consumers' surplus. The relationship between the dominant marketer's private goal of profit maximization and the social goals of efficient use of resources (Varian, 2003, p. 585) is imbalanced. The issue of equal pricing in the information economy is a complex one that demonstrates unique characteristics deserving special managerial attention and consideration of consumer welfare.

\section{Acknowledgement}

The helpful comments of an anonymous referee, both in the development of the propositions and in the precision of the descriptions, are gratefully acknowledged.

\section{Notes}

1 Varian (1997) proposed versioning as an approach to price-discriminate consumers according to their unobserved heterogeneity in willingness to pay. It is proven that consumer welfare will be reduced by versioning if it is feasible to serve both subgroups under flat pricing. Therefore, in the absence of price or quality discrimination, $\mathrm{C}_{2}$ consumers in the current study should be made better off, which is a result consistent with our assertion. 


\section{References}

American Demographics: 1999, 'PC Banking's Next Wave', 21, 16-17.

Amesse, F., C. Desranleau, H. Etemad, Y. Fortier and L. Seguin-Dulude: 1991, 'The Individual Inventor and the Role of Entrepreneurship: A Survey of the Canadian Evidence', Research Policy 20, 13-27.

Avery, C., P. Resnick and R. Zeckhauser: 1999, 'The Market for Evaluations', The American Economic Review 89, 564-584.

Bakos, Y. and E. Brynjolfsson: 1999, 'Bundling Information Goods: Pricing, Profits, and Efficiency', Management Science 45, 1613-1630.

Bakos, Y. and E. Brynjolfsson: 2000, 'Bundling and Competition on the Internet', Marketing Science 19, 63-82.

Brynjolfsson, E.: 1996, 'The Contribution of Information Technology to Consumer Welfare', Information Systems Research 7, 281-300.

Bushy, A. and J. Kamphuis: 1993, 'Response to Innovation: Behavioral Patterns’, Nursing Management 24, 62-64.

Caudill, E. M. and P. E. Murphy: 2000, 'Consumer Online Privacy: Legal and Ethical Issues', Journal of Public Policy and Marketing 19, 7-19.

Dewan, R., M. Freimer and A. Seidmann: 2000, 'Organizing Distribution Channels for Information Goods on the Internet', Management Science 46, 483-495.

Goldsmith, R. E. and S. J. Newell: 1997, 'Innovativeness and Price Sensitivity: Managerial, Theoretical and Methodological Issues', Journal of Product and Brand Management 6, 163-174.

Grewal, D. and L. D. Compeau: 1999, 'Pricing and Public Policy: A Research Agenda and an Overview of the Special Issue', Journal of Public Policy and Marketing 18, 3-10.

Grover, V. and P. Ramanlal: 1999, 'Six Myths of Information and Markets: Information Technology Networks, Electronic Commerce, and the Battle for Consumer Surplus', MIS Quarterly 23, 465-495.

Guiltinan, J. P. and G. J. Gundlach: 1996, 'Aggressive and Predatory Pricing: A Framework for Analysis', Journal of Marketing 60, 87-102.

Howell, J.: 1991, 'Potential Profitability and Decreased Consumer Welfare through Manufacturers' Centsoff Coupons', The Journal of Consumer Affairs 25, 164-184.

Jain, D. C., E. Muller and N. J. Vilcassim: 1999, 'Pricing Patterns of Cellular Phones and Phonecalls: A Segment-Level Analysis', Management Science 45, 131-141.
Kahneman, D., J. L. Knetsch, R. H. Thaler, H. Kunreuther, R. D. Luce and R. A. Shweder: 1986, 'Fairness and the Assumptions of Economics/Comments', The Journal of Business 59, S285-324.

Kotler, P.: 2000, Marketing Management, (Prentice-Hall, Englewood Cliffs, NJ).

Kulkarni, S. P.: 2000, 'The Influence of Information Technology on Information Asymmetry in Product Markets', The Journal of Business and Economic Studies 6, 55-71.

Kuznesof, S. and C. Ritson: 1996, 'Consumer Acceptability of Genetically Modified Foods with Special Reference to Fanned Salmon', British Food Journal 98, 39-47.

Martinez, E. and Y. Polo: 1996, 'Adopter Categories in the Acceptance for Consumer Durables', Journal of Product and Brand Management 5, 34-47.

Masuda, Y. and S. Whang: 1999, 'Dynamic Pricing for Network Service: Equilibrium and Stability', Management Science 45, 857-869.

Morrison, P. D., J. H. Roberts and E. Hippel: 2000, 'Determinants of User Innovation and Innovation Sharing in a Local Market', Management Science 46, 1513-1527.

Ortmeyer, G., J. A. Quelch and W. Salmon: 1991, 'Restoring Credibility to Retail Pricing', Sloan Management Review 33, 55-66.

Rogers, E. M. 1983, Diffusion of Innovations, (Free Press, New york).

Shapiro, C. and H. R. Varian: 1999, Information Rules: A Strategic Guide to the Network Economy, (Harvard Business School Press, Boston).

Sinha, I.: 2000, 'Cost Transparency: The Net's Real Threat to Prices and Brands', Harvard Business Review 78, 43-50.

Smith, A. B.: 1999, 'Net Worth: Shaping Markets When Customers Make the Rules', Journal of Public Policy and Marketing 18, 275-277.

Stiroh, K.: 1999, 'Is there a New Economy?' Challenge 42, 82-101.

Streeter, L. A., R. E. Kraut, H. C. Lucas, Jr. and L. Caby: 1996, 'How Open Data Networks Influence Business Performance and Market Structure', Communications of the ACM 39, 62-74.

Teschler, L.: 2000, 'New Role for B-to-B Exchanges: Helping Developers Collaborate', Machine Design 72, 52-61.

Truman, G. E.: 2000, 'Integration in Electronic Exchange Environments', Journal of Management Information Systems 17, 209-244.

Varian, H. R.: 1974, 'Equity, Envy, and Efficiency', Journal of Economic Theory 9, 63-91. 
Varian, H. R.: 1985, 'Price Discrimination and Social Welfare', The American Economic Review 75, 870-875.

Varian, H. R.: 1997, 'Versioning Information Goods', paper prepared for Digital Information and Intellectual Property.

Varian, H. R.: 1992, Microeconomic Analysis, (W.W. Norton \& Company, New york).

Varian, H. R.: 2001, 'High-Technology Industries and Market Structure', paper prepared for Federal Reserve Bank of St. Louis, Jackson Hole Symposium.
Varian, H. R.: 2003, Intermediate Microeconomics: A Modern Approach, (W.W. Norton \& Company, New york).

Department of Information Management, National Taiwan University, Taipei 106, Taiwan E-mail:huangmh@ntu.edu.tw 